\title{
Biodegradation of high-concentration isopropanol by a solvent-tolerant thermophile, Bacillus pallidus
}

\author{
Mark T. Bustard, Samantha Whiting, Don A. Cowan, Phillip C. Wright
}

\begin{abstract}
The aerobic biodegradation of high-concentration, to $24 \mathrm{~g} \mathrm{l}^{-1}, 2$-propanol (IPA) by a thermophilic isolate ST3, identified as Bacillus pallidus, was successfully carried out for the first time. This solvent-tolerant $B$. pallidus utilized IPA as the sole carbon source within a minimal salts medium. Cultivation was carried out in $100-\mathrm{ml}$ shake flasks at $60^{\circ} \mathrm{C}$ and compared with cultivation within a 1-1 stirred tank reactor (STR). Specific growth rate $(\mu)$ was about $0.2 \mathrm{~h}^{-1}$ for both systems, with a maximum cell density of $2.4 \times 10^{8} \mathrm{cells} \mathrm{ml}^{-1}$ obtained with STR cultivation. During exponential growth and stationary phase, IPA biodegradation rates were found to be 0.14 and $0.02 \mathrm{~g} \mathrm{l}^{-1} \mathrm{~h}^{-1}$, respectively, in shake-flask experiments, whereas corresponding values of 0.09 and $0.018 \mathrm{~g} \mathrm{l}^{-1} \mathrm{~h}^{-1}$ were achievable in the STR. Generation of acetone, the major intermediate in aerobic IPA biodegradation, was also monitored as an indicator of microbial IPA utilization. Acetone levels reached a maximum of 2.2-2.3 $\mathrm{g} \mathrm{l}^{-1}$ after 72 and $58 \mathrm{~h}$ for 100-ml and 1-1 systems, respectively. Both IPA and acetone were completely removed from the medium following 160 and $175 \mathrm{~h}$, respectively, during STR growth, although this was not demonstrated within shake-flask reactions. Growth of B. pallidus on acetone or IPA alone demonstrated that the maximum growth rate $(\mu)$ obtainable was $0.247 \mathrm{~h}^{-1}$ at $4 \mathrm{~g} \mathrm{l}^{-1}$ acetone and $0.202 \mathrm{~h}^{-1}$ at $8 \mathrm{~g} \mathrm{l}^{-1} \mathrm{IPA}$ within shake-flask cultivation. These results indicate the potential of the solvent-tolerant thermophile B. pallidus ST3 in the bioremediation of hot solvent-containing industrial waste streams.
\end{abstract}

Key words Bacillus pallidus; Biodegradation; Isopro-panol (IPA); Solvent tolerant; Thermophilic; Volatile organic compounds (VOCs)

\section{Introduction}

Volatile organic compound (VOC) emissions are becoming increasingly more regulated, thus forcing technologists to assess more efficient and economic process options (Kiared et al. 1997). The most widely used VOC is 2-propanol, or isopropyl alcohol (IPA), whose production worldwide exceeds 1 million tonnes per annum, through its many industrial uses as a cheap ethanol replacement for solvent, intermediate, de-icer, and applications in rubber, cosmetics, textiles, pharmaceuticals, and fine chemicals industries (Harris 1991; Derwent and Pearson 1997).

Biological treatment of IPA-containing waste streams can be advantageous (Lobos et al. 1992), but little information is available on this process at high temperature and high solvent concentration, despite several successful meso-philic anaerobic studies involving co-metabolism with glucose (Fox and Ketha 1996; Ueyama et al. 1971). Although IPA and toluene are typical solvents conveniently used for sterilization, 
some microorganisms may assimilate these toxic compounds at low concentrations (Kanemitu et al. 1980; Murrays et al. 1980). This process is described in more detail elsewhere (Bustard et al. 2000).

In order to develop both conventional and novel bio-reactors, substrate transport phenomena, biodegradation rates, and biomass growth must be mechanistically-scaled (Dolfing and Janssen 1994; Fujita et al. 1992; Singleton 1994). Quantification of bioconversion kinetics is essential in waste gas biofiltration or wastewater treatment system design, with both single- and multi-substrate biodegrada-tion applications demonstrated (Guha et al. 1999).

Previous studies involving Bacillus pallidus strains have examined the characterization of their thermostable nitrile hydratase and nitrilase enzymes (Cramp and Cowan 1999; Almatawah and Cowan 1999). However, the potential of B.pallidus in pollution abatement systems has been generally overlooked, with only hot composting, pinene (to $2 \mathrm{gl}^{-1}$ ), and phenol (to $3 \mathrm{~g} \mathrm{l}^{-1}$ ) degradation applications mentioned in the current literature (Ali et al. 1998; Savithiry et al. 1998; Blanc et al. 1997). By and large, thermophilic bacteria are often applied in waste stream treatment systems, such as gas biofiltration and anaerobic digesters (Dhamwichukorn et al. 2001; Han and Dague 1997). Here we describe, for the first time, the aerobic thermophilic biodegradation of high concentrations of IPA by a B. pallidus isolate, focusing on specific growth rate, IPA biodegradation, and acetone generation. The scale-up fermentation of this thermophile utilizing high-concentration IPA as the sole carbon source, the effect on cell growth, and the effect on IPA degradation rate are also described.

\section{Materials and methods}

Isolation of microorganism

The thermophilic strain was isolated from a phenol-contaminated industrial effluent lake (Huntly, New Zealand), and identified as described previously by Ali et al. (1998). Single colony-forming units were selected from nutrient agar plates $\left(13 \mathrm{~g} \mathrm{l}^{-1}\right.$ nutrient broth, $1.2 \%(\mathrm{w} / \mathrm{v})$ bacteriological agar; Difco) inoculated with this IPA-utilizing B. pallidus strain. Subsequently, this pure strain was cultivated at $60^{\circ} \mathrm{C}\left(\mathrm{T}_{\text {optimum }}\right.$ - data not shown) in submerged culture, and examined under an Olympus $\mathrm{CH}-2$ light microscope to ensure single strain purity. This was carried out both prior to inoculation and following conclusion of the reaction.

\section{Enrichment procedure}

The B. pallidus ST3 isolate was initially cultivated in $13 \mathrm{gl}^{-1}$ nutrient broth (Oxoid, UK) in a lateral shaking water bath set at $150 \mathrm{rpm}$ and $60^{\circ} \mathrm{C}$. All media was auto-claved at $121^{\circ} \mathrm{C}, 1 \mathrm{~atm}$ for $15 \mathrm{~min}$ and allowed to cool to $60^{\circ} \mathrm{C}$ prior to inoculation. Cycles of growth were carried out with $1 \%(\mathrm{v} / \mathrm{v})$ inoculum added to 100 $\mathrm{ml}$ of $13 \mathrm{~g} \mathrm{l}^{-1}$ nutrient broth (Difco) in 250-ml Erlenmeyer flasks at $60^{\circ} \mathrm{C}$. which were then converted to cell number (cells $\mathrm{ml}^{-1}$ ) using a calibration curve. Controls containing MSM and either 2-24. $\mathrm{gl}^{-1} \mathrm{IPA}$ or acetone were set up to correct for volatilization and evaporative loss during the course of the experiment. These volatilization controls then allowed true bacterial biodegradation rate to be determined rather than combined volatilization/biodegradation. These true values are depicted in the Figures. 
IPA and acetone concentrations were determined using a Shimadzu GC-17A gas chromatograph equipped with a Carbowax BP20 capillary column (length $30 \mathrm{~m}$; i.d. $0.53 \mathrm{~mm} ; 1$ i $\mathrm{m}$ film). Flow rate of He carrier gas was $11 \mathrm{ml} \mathrm{min}^{-1}$, the temperatures of the flame ionization detection (FID) system and injection port were $280^{\circ} \mathrm{C}$. The oven temperature was $80^{\circ} \mathrm{C}$ and sample run time was $2 \mathrm{~min}$. Typically, $1 \mathrm{ml}$ of culture was extracted from each reaction at specified time intervals, cells were spun down in an Eppendorf benchtop microcentrifuge at $12,000 \mathrm{xg}$, and a 1 sample of supernatant injected into the gas chromato-graph for analysis. Samples were extracted and analyzed in triplicate.

\section{Batch fermentation scale-up}

An autoclaved 1-1 stirred tank reactor (STR) containing $800 \mathrm{ml}$ MSM was inoculated with $10 \mathrm{ml}$ of culture $\left(1.4 \times 10^{7}\right.$ cells ml-1). Filtered (0.2 um) air was supplied at a rate of $0.021 \mathrm{~min}^{-1}$ and the reaction mixture stirred by an impeller and overhead motor $(\mathrm{OKI})$ at $150 \mathrm{rpm}$. The STR temperature was maintained at $60^{\circ} \mathrm{C}$ by means of a water jacket, and gas vented via a 0.45 -um filter to maintain sterility. Biodeg-radation of IPA was carried out through batch addition of $8.8 \mathrm{ml} \mathrm{IPA} \mathrm{solvent} \mathrm{to} \mathrm{give} \mathrm{a} \mathrm{final} \mathrm{concentration} \mathrm{of} 8 \mathrm{~g} \mathrm{l}^{-1}$ in the reaction vessel. Identical control reactors were set up simultaneously with IPA or acetone alone, under the same conditions but without B. pallidus inoculum, to determine volatilization and evaporative loss rate under reaction conditions. These evaporation rates were then subtracted from combined volatilization/biodegradation rates to obtain true microbial biodegradation rates as depicted in the Figures. Experiments were carried out three times.

\section{Solvent degradation experiments}

Several 250-ml shake flasks were set up in at least triplicate containing 0-24 $\mathrm{g} \mathrm{l}^{-1} \mathrm{IPA}$ or acetone within a 100-ml minimal salts medium (MSM), as described by Bustard et al. (2000), and $1 \mathrm{ml}$ of inoculum (1.4 x $10^{7}$ cells $\mathrm{ml}^{-1}$ ) added. IPA or acetone was added as the sole carbon nutrient source. Flasks were stoppered with foam bungs, covered in aluminum foil, and placed within a variable-temperature shaking incubator at $60^{\circ} \mathrm{C}$ for the duration of the experiment. Samples were taken periodically for cell number and solvent concentration analysis. Cell growth was measured using $\mathrm{OD}_{450}$ values, as described by Bustard et al. (2000), Nucleotide sequence accession number

The partial 16S rDNA gene sequence obtained for B. pallidus ST3, utilizing methodology described by Rainey et al. (1994), has been deposited in the GenBank database under accession number AF380929.

\section{Results}

After numerous serial transfers during a 6-month period, a bacterial strain, designated ST3, capable of growth in the presence of $8 \mathrm{~g} \mathrm{l}^{-1}$ IPA was isolated. Partial 16S rDNA sequencing over $600 \mathrm{bp}$ revealed 99\% 
homology to B. pallidus and displayed a close relationship to other thermophilic Bacillus spp. (Ali et al. 1998; Rainey et al. 1994).

This $B$. pallidus isolate demonstrated the ability to grow on high-concentration IPA as the sole carbon source when grown in shake-flask culture at $60^{\circ} \mathrm{C}$. Figure 1 (after References) shows that exponential phase growth is initiated following a 23 -h lag phase. The specific growth rate of B. pallidus on IPA was calculated to be $0.202 \mathrm{~h}^{-1}$ by taking the slope of the exponential growth phase. It was also demonstrated that a maximum cell density of $1.8 \times 10^{8} \mathrm{ml}^{-1}$ was achievable during shake-flask cultivation on $8 \mathrm{~g} \mathrm{l}^{-1} \mathrm{IPA}$ solvent. During cell growth in exponential phase through to stationary phase, a maximum IPA biodegradation rate of $0.141 \mathrm{~g} \mathrm{l}^{-1} \mathrm{~h}^{-1}$ was exhibited. However, the rate of IPA utilization during stationary phase (steady state) was reduced to $0.021 \mathrm{~g} \mathrm{l}^{-1} \mathrm{~h}^{-1}$, more than six times lower than that demonstrated during the exponential phase.

The presence of acetone, the major intermediate of aerobic IPA biodegradation (Steffan et al. 1997), was also monitored throughout the experiment, and was found to appear after $24 \mathrm{~h}$ of cultivation (Fig. 1). Acetone reached a maximum level of $2.2 \mathrm{~g} \mathrm{l}^{-1}$ following $72 \mathrm{~h}$ of reaction, and was then found to be utilized as a substrate itself by $B$. pallidus, showing a concentration reduction during the stationary phase of cell growth between 72 and $144 \mathrm{~h}$. Cell death was initiated at $154 \mathrm{~h}$, with final IPA and acetone concentrations of 0.32 and $1.15 \mathrm{gl}^{-1}$ present, respectively. All biodegradation experiments were corrected for IPA and acetone volatilization and evaporative loss.

A comparison of B. pallidus specific growth rates, $\mathrm{L}\left(\mathrm{h}^{-1}\right)$, for acetone and IPA alone over the concentration range $0-24 \mathrm{gl}^{-1}$ solvent in shake-flask cultivation experiments is depicted in Fig. 2 (after References). At initial solvent concentrations to $8 \mathrm{~g} \mathrm{l}^{-1}$, more rapid cell growth is observed when acetone is the sole carbon source, with $\mathrm{m}$ values of up to $0.247 \mathrm{~h}^{-1}$ obtainable, whereas B. pallidus growth on IPA is maximal at an

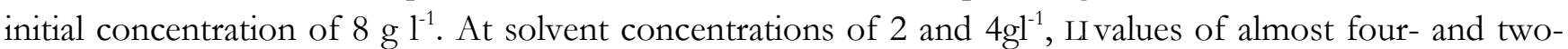
fold higher, respectively, for acetone over IPA are demonstrated. Acetone is clearly observed to be the preferred substrate over IPA at low initial solvent concentrations, although this was not the case at significantly higher solvent concentrations (to $24 \mathrm{gl}^{-1}$ ). At these substrate conditions, IPA displayed higher U values of 0.071 and $0.011 \mathrm{~h}^{-1}$ at 16 and $24 \mathrm{~g} \mathrm{l}^{-1} \mathrm{IPA}$, respectively, in comparison with reduced values of 0.04 and $0.005 \mathrm{~h}^{-1}$ for acetone at similar concentrations. This indicates that high concentrations of acetone as the sole carbon source have a greater inhibitory effect on B. pallidus growth than similar concentrations of IPA.

In order to ensure more effective control during the B. pallidus fermentation, cultivation was carried out within a 1-1 STR at $8 \mathrm{~g} \mathrm{l}^{-1}$ IPA as the sole carbon source, since the highest Lvalues had been obtained in previous shake-flask cultivation. Aeration and agitation parameters were optimized (data not shown) to ensure high-efficiency bio-degradation of IPA and acetone by B. pallidus. It was demonstrated that higher cell biomass was achievable under these conditions (Fig. 3), where $2.4 \times 10^{8} \mathrm{ml}^{-1}$ was obtained (a 33\% increase over the shake-flask growth). The specific growth rate of B. pallidus in 1-1 batch STR culture was $0.199 \mathrm{~h}^{-1}$, very similar to that obtained for $100-\mathrm{ml}$ shake-flask cultivation $\left(0.202 \mathrm{~h}^{-1}\right)$. However, the IPA biodegradation rates were significantly reduced (by 30\%) during the scale-up reaction, where the rate calculated during exponential phase of growth was $0.099 \mathrm{~g} \mathrm{l}^{-1} \mathrm{~h}^{-1}$ as opposed to $0.141 \mathrm{~g} \mathrm{l}^{-1} \mathrm{~h}^{-1}$ at $100-\mathrm{ml}$ volume. Furthermore, IPA biodeg-radation by B. pallidus proceeded at $0.018 \mathrm{~g} \mathrm{l}^{-1} \mathrm{~h}^{-1}$ during stationary growth phase (steady state), a conversion reduction of $3 \times 10^{-3} \mathrm{gl}^{-1} \mathrm{~h}^{-1}$ for IPA. This is especially interesting 
given that there was a 30\% greater biomass concentration in the 1-1 STR. Further studies into cell damage and viability are currently under way within our laboratory in an attempt to form a mechanistic understanding of this problem.

Acetone was found to be produced after $26 \mathrm{~h}$, reaching a maximum level of $2.3 \mathrm{~g} \mathrm{l}^{-1}$ following $58 \mathrm{~h}$ of reaction (Fig. 3, after References). The maximum acetone level was achieved $14 \mathrm{~h}$ earlier during cultivation within the 1-1 STR and this substrate was itself utilized to completion at $175 \mathrm{~h}$. All IPA was effectively removed from the medium following a cultivation time of $160 \mathrm{~h}$, and B. pallidus stationary phase was achievable between 70 and $170 \mathrm{~h}$ without the onset of cell death. However, although the scale-up reaction was successfully carried out at 11 , the lower IPA biodegradation rate observed during exponential growth was $0.042 \mathrm{~g} \mathrm{l}^{-1} \mathrm{~h}^{-1}$ less than that experienced with $100-\mathrm{ml}$ cultivation. Comparison of Figs. 1 and 3 demonstrates that the onset of stationary phase during $1-1$ cultivation occurs at $70 \mathrm{~h}$ as opposed to $60 \mathrm{~h}$, as observed in smaller-scale cultivation.

\section{Discussion}

Cultivation of the thermophile B. pallidus was successfully achieved under aerobic conditions using IPA or acetone as the sole carbon source at $60^{\circ} \mathrm{C}$. This strain exhibited a degree of solvent tolerance, since solvent was present in the medium at concentrations up to $24 \mathrm{~g} \mathrm{l}^{-1}$, where cell densities above $10^{8} \mathrm{ml}^{-1}$ were demonstrated. No previous reports of IPA tolerance by thermophilic Bacilli are currently available in the literature, although Bacillus DS-994, isolated from deep-sea sediment samples, has demonstrated growth in the presence of 5\%(v/v) benzene and 10\% (v/v) toluene (Moriya and Horikoshi 1993). Here, we demonstrate not only cellular growth in the presence of high-concentration IPA and acetone, but also their utilization as the sole carbon source by B. pallidus. Comparison of specific growth rates for B. pallidus on acetone or IPA alone showed that acetone was a preferred substrate at concentrations to $8 \mathrm{gl}^{-1}$, although above this it exhibited greater inhibitory affects on $\mu$ values, indicating higher toxicity than IPA above $16 \mathrm{~g}$ $\mathrm{I}^{-1}$. Furthermore, order of magnitude greater cultivation reactions were successfully applied in order to optimize the biodegradation of $8 \mathrm{~g} \mathrm{l}^{-1}$ IPA within a 1-1 STR. However, although aeration and mass transfer are increased within a stirred tank reactor, shear forces may also have a detrimental effect on cell growth. Althouth the achievable cell density was increased significantly during scale-up, a later onset of stationary growth phase was demonstrated within the STR than that observed for shake-flask cultures. This may be due to shear stress caused by the mechanical impeller within the vessel, since the aeration rate was sufficient to ensure that oxygen limitation did not occur. This increased aeration also seems to ensure a prolonged stationary period prior to cell death, which benefits the biodegradation reaction sufficiently to ensure that both IPA and acetone are completely utilized. The biodegradation rate has implications with regard to residence time and metabolite production for bioreactor operation in pollution abatement systems such as wastewater treatment or gas biofiltration. In addition, the ability of these solvent-tolerant bacteria to withstand higher fluctuations in pollutant levels, at the elevated temperatures often found industrially, should enable more efficient operation of such systems. Steffan et al. (1997) also suggest that IPA is converted to acetone, which in turn is converted to pyruvic acid and enters directly into the TCA cycle. Although Fox and Ketha (1996) demonstrated the microbial biodegradation of IPA under anaerobic conditions at $30^{\circ} \mathrm{C}$, the highest conversion values were through co-metabolism of $1.5 \mathrm{~g} \mathrm{l}^{-1} \mathrm{IPA}$ with $1 \mathrm{~g} \mathrm{l}^{-1}$ glucose. Here, we demonstrate for the first time the ability of the aerobic thermophile B.pallidus to utilize 
high concentrations of IPA and acetone at $60^{\circ} \mathrm{C}$, with no further additional carbon supplementation under conditions that may be considered solvent-tolerant.

Acknowledgments P.C.W. and M.T.B. would like to thank the UK's Biotechnology and Biological Sciences Research Council (BBSRC) for financial support (grant no. 97/E11124), and Sutcliffe Croftshaw Ltd (Lancashire, UK) for technical advice on biofiltration.

\section{References}

Ali S, Fernandez-Lafuente R, Cowan DA (1998) Meta-pathway degradation of phenolics by thermophilic Bacilli. Enzyme Microb Technol 23:462-468

Almatawah Q, Cowan D (1999) Thermostable nitrilase catalysed production of nicotinic acid from 3cyanopyridine. Extremophiles25:718-724

Blanc M, Marilley L, Beffa T, Aragno M (1997) Rapid identification of heterotrophic, thermophilic, sporeforming bacteria isolated from hot composts. Int J Syst Bacteriol 47:1246-1248

Bustard MT, McEvoy EM, Goodwin JAS, Burgess JG, Wright PC (2000) Biodegradation of propanol and isopropanol by a mixed microbial consortium. Appl Microbiol Biotechnol 54:424-431

Cramp R, Cowan D (1999) Molecular characterisation of a novel thermophilic nitrile hydratase. Biochim Biophys Acta 1431:249260

Derwent RG, Pearson JK (1997) Improving air quality in the United Kingdom - the solvents contribution. Environ Technol 18:1029-1036

Dhamwichukorn S, Kleinheinz GT, Bagley S (2001) Thermophilic bio-filtration of methanol and alphapinene. J Ind Microbiol Biotechnol 26:127-133

Dolfing J, Janssen DB (1994) Estimates of Gibbs free energies of formation of chlorinated aliphatic compounds. Biodegradation 5:21-28

Fox P, Ketha S (1996) Anaerobic treatment of high-sulphate waste-water and substrate interactions with isopropanol. J Environ Eng 122:989-994

Fujita M, Ike M, Kayima T (1992) Accelerated phenol removal by amplifying the metabolic pathway with a recombinant plasmid encoding catechol 2,3 oxygenase. Water Sci Technol 26:2191-2194

Guha S, Peters CA, Jaffe PR (1999) Multisubstrate biodegradation kinetics of naphthalene, phenanthrene and pyrene mixtures.Biotechnol Bioeng 5:491-499

Han Y, Dague R (1997) Laboratory studies on the temperature phased anaerobic digestion of domestic primary sludge. Water Environ Res 69:1139-1143

Harris JW (1991) Hydrocarbon production handbook. Hydrocarbon Process 64:154

Kanemitu H, Fukuda M, Yano K (1980) Plasmid-borne biodegradation of toluene and ethylbenzene in a Pseudomonas. J Ferment Technol 57:175-181

Kiared K, Wu G, Beerli M, Rothenbuhler M, Heitz M (1997) Application of biofiltration to the control of VOC emissions. Environ Technol 18:55-63

Lobos JH, Leib TK, Su T-M (1992) Biodegradation of bisphenol A and other bisphenols by a gramnegative aerobic bacterium. Appl Environ Microbiol 58:1823-1831

Moriya K, Horikoshi K (1993) Isolation of a benzene-tolerant bacterium and its hydrocarbon degradation. J Ferment Bioeng 76:168-173

Murrays J, Roberta A, Hall AA, Griffini M (1980) Microbial metabolism by a pure strain of Pseudomonas sp. J Gen Microbiol 120:89-94 
Rainey FA, Fritze D, Stackebrandt E (1994) The phylogenetic diversity of thermophilic members of the genus Bacillus as revealed by $16 \mathrm{~S}$ rDNA analysis. FEMS Microbiol Lett 115:205-211

Savithiry N, Gage D, Fu W, Oriel P (1998) Degradation of pinene by Bacillus pallidus BR425. Biodegradation 9:337-341

Singleton I (1994) Microbial metabolism of xenobiotics: fundamental and applied research. J Chem Technol Biotechnol 59:9-23

Steffan RJ, McClay K, Vainberg S, Condee CW, Zhang D (1997) Biodegradation of the gasoline oxygenates methyl tert-butyl ether, ethyl tert-butyl ether and tert-amyl methyl ether by propane-oxidizing bacteria. Appl Environ Microbiol 63:4216-4222

Ueyama H, Yamauti Y, Tuki N, Fukimbara T (1971) Studies on the fermentation of petrochemicals. I.

Taxonomic studies on Arthrobacter sp. isolated from soil. J Ferment Technol 49:581-586

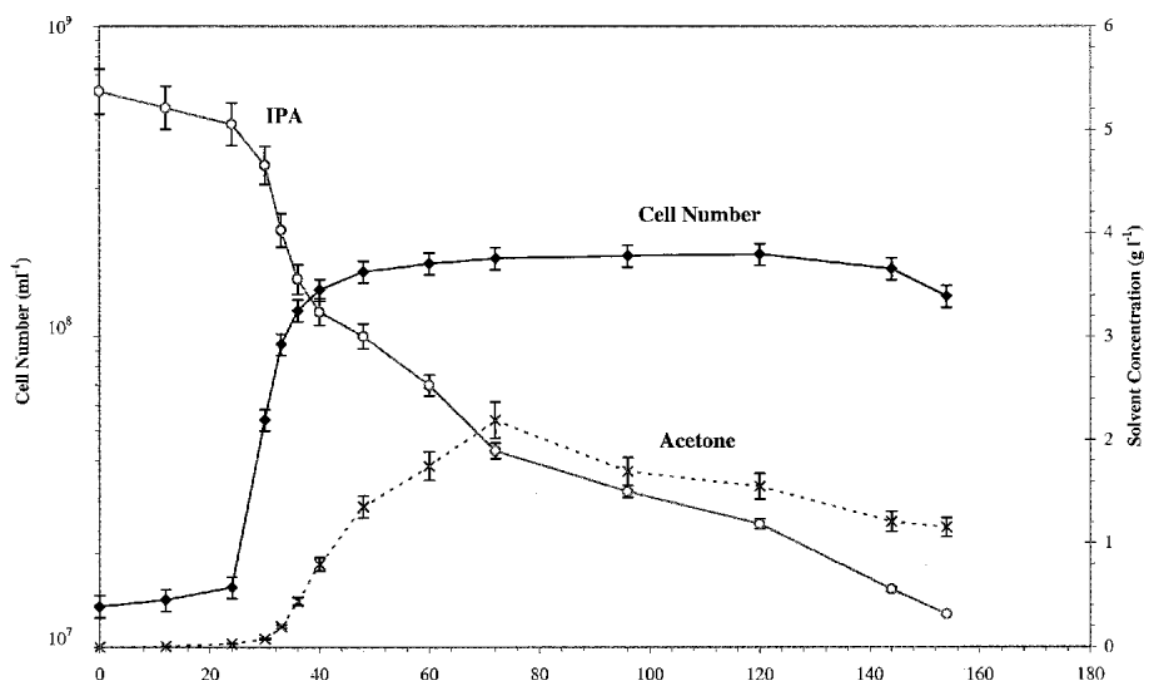

Fig. 1. Biodegradation of $8 \mathrm{~g} \mathrm{l}^{-1}$ isopropyl alcohol (IPA) by the solvent-tolerant thermophile Bacillus pallidus within $100-\mathrm{ml}$ reaction volume at $60^{\circ} \mathrm{C}$. IPA concentration (circles), acetone concentration (crosses), and cell growth (diamonds) are depicted. All experiments were carried out in triplicate, and corrected for volatilization and evaporative loss for both IPA and acetone 


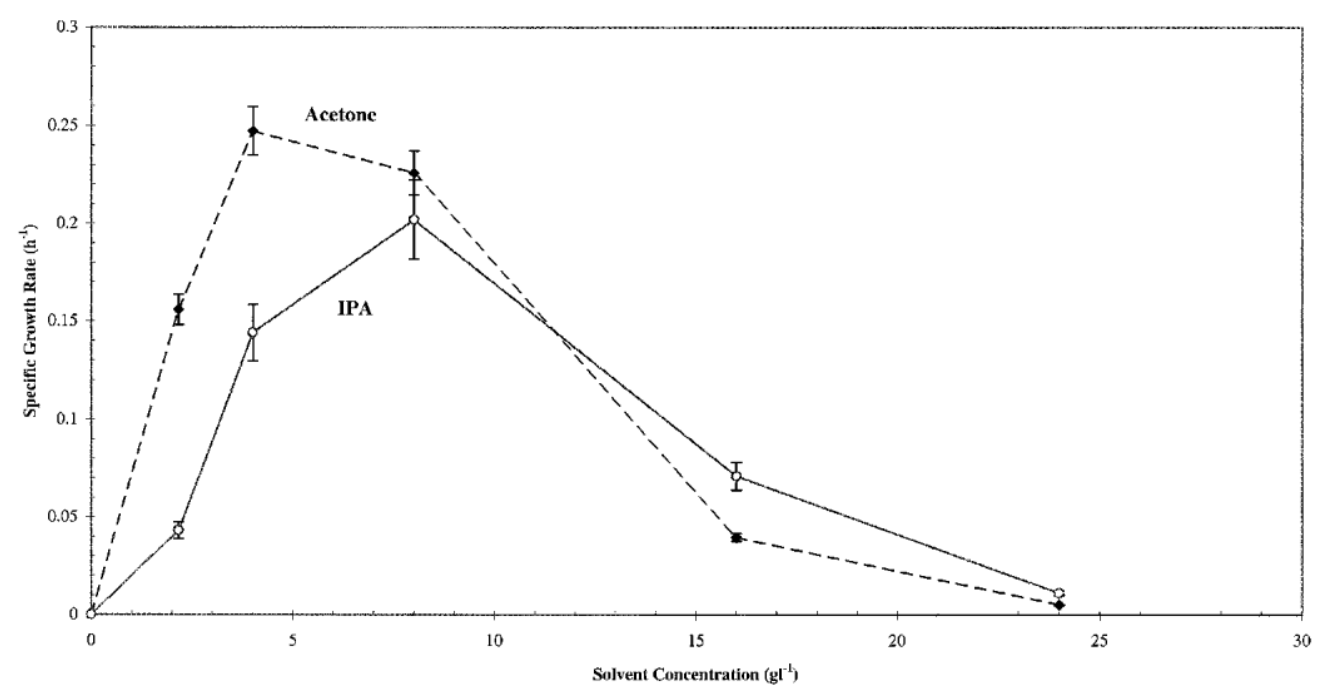

Fig. 2. Specific growth rate, $\mid \mathrm{i}\left(\mathrm{h}^{-1}\right)$, of $B$. pallidus as a function of initial solvent concentration $\left(\mathrm{g}^{-1}\right)$ for either acetone (diamonds) or IPA (circles). All experiments were carried out in triplicate shake flasks as detailed previously, and corrected for volatilization and evaporative loss for both IPA and acetone solvents

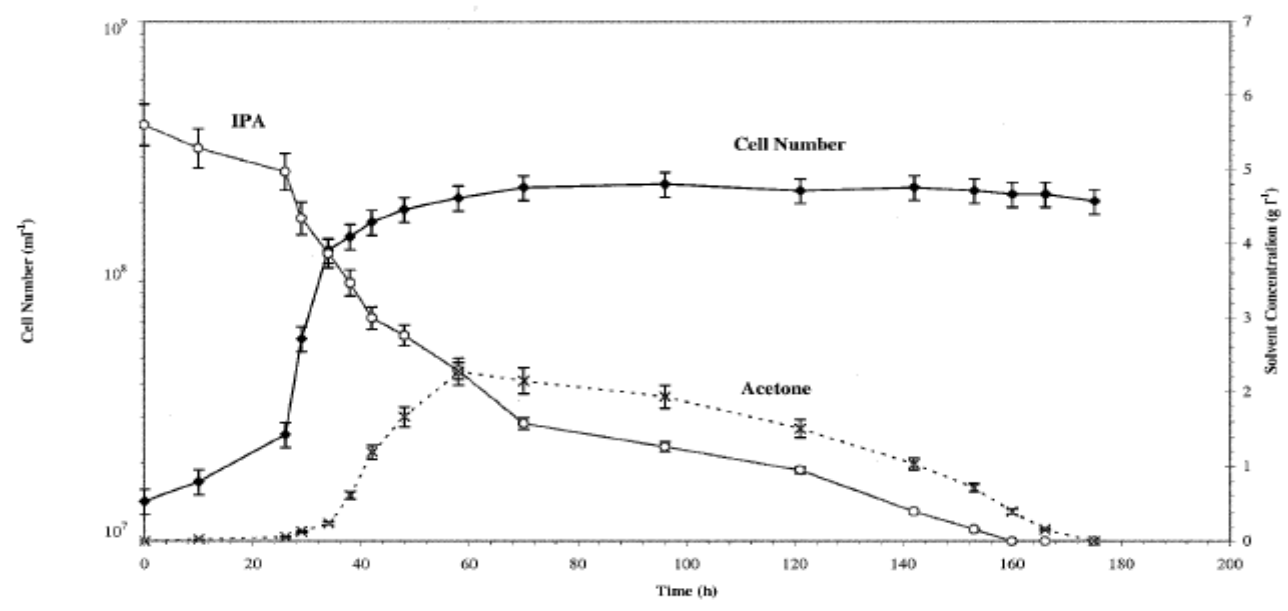

Fig. 3. Cultivation of the solvent-tolerant B. pallidus within a $1-1$ stirred tank reactor (STR) at $60^{\circ} \mathrm{C}$ using $8 \mathrm{~g} 1-1 \mathrm{IPA}$ as the sole carbon source. IPA concentration (circles), acetone concentration (crosses), and cell growth (diamonds) are shown. All cultivation experiments were carried out in triplicate, and corrected for IPA and acetone volatilization and evaporative loss 